\title{
The Experience of International Student Using Social Media during Classes
}

\author{
Yousef T. Alfarhoud ${ }^{1, *}$, Badr Alahmad ${ }^{1}$, Latifah Alqahtani ${ }^{1,2} \&$ Abdulaziz Alhassan $^{1}$ \\ ${ }^{1}$ Dept. of Library and Information sciences, University of North Texas, 1155 Union Circle, \\ \#311277, Denton, TX, 76203-5017, USA \\ ${ }^{2}$ P.h. D candidate of Universty of North Texas and a scholarship holder from Princess Nourah \\ bint Abdulrahman University. \\ *Correspondence: Dept. of Library and Information sciences, University of North Texas, \\ 1155 Union Circle, \#311277, Denton, TX, 76203-5017, USA. Tel: 1-469-226-6776. E-mail: \\ YAlfarhoud@gmail.com
}

Received: March 30, 2016 Accepted: April 16, 2016 Published: May 14, 2016

doi:10.5296/ije.v8i2.9224 URL: http://dx.doi.org/10.5296/ije.v8i2.9224

\begin{abstract}
The purpose of the study is to explore the use of social media by international students during classes and discern the pros and cons of their use of social media. An explanatory sequential mixed methods design is used to give evidence about the research problem starting with a quantitative method (questionnaire) and then a qualitative method (semi-structured interviews). The study shows that $64.4 \%$ of international students used social media during classes while $35.6 \%$ did not. In terms level of satisfaction, the study result shows that males and females were not significant different in this regard. Additionally, most of the participants $57.4 \%$ used social media for $1-10$ minutes, while $27.7 \%$ used them for 11 to 30 minutes of class time. Some international students used social media for coping with the weakness of their knowledge during class time, whereas the majority of them indicated that they used social media for surviving the transition of relocating form their own countries to United State as sojourners by stating that they used social media to stay connected with and informed about their family, friends, and country news and events. The use of social media during classes should be integrated with the learning environment, especially regarding the motivation of use, which can potentially provide success in overcoming most reasons for frustration and home sickness.
\end{abstract}

Keywords: International student, Social media, Education, Distraction tools 


\section{Introduction}

Technology, in its variety of forms, has impacted our daily lives. People have become accustomed to adapting to different applications to help them organize their duties and complete them with less effort. The rapid change in technology applications within a short period of time, as well as the crucial role it plays in shaping our way of communicating, is clear to see. Social network sites have exploded in the past few years.

International students face many challenges during their time away from home. Language barriers, culture shock, homesickness, and academic performance challenges are examples of various difficulties that international students have to deal with. However, there are many aspects of life in foreign countries that can help reduce the negative experience of being a foreign student. One of these is the possibility of using social media to connect with loved ones. On the other hand, social media can lead to some disadvantages for people who use it inappropriately. In many situations, students find themselves able to engage in the use of social media applications during class time for a variety of purposes. Some instructors may mandate the use of these applications as among the class materials, while others might enforce a strict rule of not using them as they might distract the students. In any case, a significant number of students have the desire to check their phones regularly while in class either to find information related to the class or just to chat with friends.

This study will investigate the experience of the use of social media in class by international students. A literature review is conducted to provide a better understanding of the nature of the research problem. In addition, a methodology section is added to describe the research method, instruments used, sampling, and data analysis tools. The discussion section shows the results of the study.

\subsection{Problem Statement}

The phenomenon of social media has been exploding since 2010. Facebook, Twitter, Flickr, Instagram, and Snapchat are examples of social media websites. According to Statista (2016a), nearly two billion internet users around the world use social media; Facebook alone has almost 1.550 billion, WhatsApp 900 million, Instagram 400 million, Twitter 320 million, and Snapchat 200 million active accounts. Users of these media have the ability to interact with each other anytime, anywhere. On both mobile and web-based platforms, social media applications are emerging as great tools for communicating with as they provide various ways to share, exchange, and create information among individuals. The simple press of a button makes it possible to share interesting, vast, and dynamic information to hundreds, thousands, and even millions of other individuals utilizing the same social media sites. Information sharing via social media has become a part of users' everyday life and has become a need for many. In addition, users need to feel updated on other people's personal lives and status.

A study by Sandhu and Asrabadi (1994) assessed the acculturative stress of international students. In addition, the study pointed out some contributing factors to acculturative stress such as homesickness and change (cultural shock). Lederer (2012) indicated that using social 
media has both advantages and disadvantages in general for all users. The article provided insights into the use of social media in education, particularly in classrooms as supportive engagement tools. However, there is a possibility that students are distanced from engagement in the class due to the use of social media. This study will address the question of why international students use social media during class time.

\subsection{Purpose of the Study}

The purpose of this study is to explore the use of social media by international students during class, specifically, to examine the experience of international students and to discover the advantages and disadvantages of using social media in the classroom. An explanatory sequential mixed methods design was used to provide evidence about the research problem. This type of method is useful to provide in-depth understanding about the use of social media in class by international students. The participants in this study were international students at a southern university in the U.S.

\subsection{Main Research Question}

The main research question is the following:

What is the experience of international students who use social media in the classroom?

\subsubsection{Research Sub-Questions}

The following are the sub-questions for this research:

What social media do international students use the most in the classroom?

Why do international students use social media?

What benefits and drawbacks do international students see in their use of social media?

\section{Literature Review}

\subsection{Social Media Use}

Technology in its variety of forms has a great impact on our daily lives. People have become accustomed to using different applications to help them organize their duties make them easier to accomplish. The rapid change in technology applications within a short period of time, and the crucial role they play in shaping our ways of communicating, is clear to see. It is important to clarify precisely what social media are in order to understand its impact and capability in our lives. According to Kaplan and Haenlein (2010), social media can be defined as "a group of Internet-based applications that build on the ideological and technological foundations of Web 2.0, and that allow the creation and exchange of user-generated content" (p.62). In both mobile and web-based platforms, social media applications are emerging as a great tool for communicating which enable the sharing, exchange, and creation of information among users. Social media has changed the way people communicate. Another definition was introduced by Boyd and Ellison (2007), and it stated 
We define social network sites as web-based services that allow individuals to (1) construct a public or semi-public profile within a bounded system, (2) articulate a list of other users with whom they share a connection, and (3) view and traverse their list of connections and those made by others within the system. The nature and nomenclature of these connections may vary from site to site (p.211).

Social network sites have exploded in the past few years. Facebook, Twitter, and Instagram are the most common examples. Users, including international students, have the ability to create and share many forms of information such as text, photos, videos, and audio at their convenience. Information sharing has become a part of everyday life, and the need to feel updated on other peoples' personal lives and behaviors is changing the way people view themselves and share information about how they behave and what their life consists of.

\subsection{Social Media Types for International Students}

It is clear that social media are affecting people's life and becoming a vital information source nowadays. They have changed the nature of communication and how individuals express their thoughts and make contact with each other; furthermore, social interaction has increased since the appearance of social media. Pardue (2012) found that people were building strong relationships through the online environment, and they have become involved in many membership groups that would not be available to them without the use of social media. To recognize what the most popular social media are, Walaski (2013) categorized the 330 different social media platforms into six popular platform types. The top one category is social networking sites that include Facebook and MySpace; they promote the building of relationships among people with similar interests and activities. The second category is that of blogs and microblogging, such as Twitter, which allows people to send text messages. Also, there is video sharing, and YouTube is the most commonly used in this kind of site. These sites enable the user to upload videos and share them with others. Wikipedia belongs to the category of content-driven communities. These sites allow editing by any user and the sharing of content for purposes of enhancing it or changing it completely.

Many studies have been conducted on the use and experience of social media among various types of users. One study explores the use of social media among international students in Bond University in Australia. The authors investigate the social networking sites preferred by international students. The study presents the results of a survey of 575 international and domestic students. Facebook was the most commonly used site for both domestic and international students, with 514 out of the 575 respondents indicating they had a Facebook account. The second most popular was YouTube, with 335 respondents indicating they had an account. Twitter and LinkedIn were third and fourth respectively. The majority of participants had had their social media accounts for more than two years with an average usage of several times a day. In terms of the reasons for using social media, the most commonly selected reasons were social activities such as chatting with friends, keeping up with friends, and staying in touch with family. In addition, $60 \%$ of the participants said they used Facebook for sharing and finding information. The top three favorite platforms were Facebook, Twitter, and YouTube. Ease of use, usefulness, and the social benefits were the reasons why international 
students preferred them. Some of the respondents' comments in this regard included:

"All my friends are using these sites." "To keep in touch with friends overseas." "Get information on my friends." "There are so many people in these networks." "They bring two people closer and in an effective way." "Everyone has an account." "Most people around me use it, so I can get in touch with more people." Interestingly, the survey found that use of social media among international students for educational purposes was much less frequent than their use for social activities.

Mixed methods have been adopted by many studies to understand why students use social media; while the literature on this topic also uses quantitative and qualitative approaches, this review will focus on studies that used mixed methods to investigate the use of social media in order to identify ways in which the methods employed by the existing studies inform their outcomes. Baggett and Williams (2012) conducted a study to investigate students' behaviors and opinions regarding the use of social media and mobile technology for library research in Shenandoah University in Virginia. Baggett and Williams (2012) adopted a mixed method approach, including an online survey and a follow-up focus group, in order to discover students' opinions toward using social media through the online survey and to then enhance the baseline information gathered from the survey and gain deeper understanding of students' behaviors through the focus group. After the analysis of the 58 item questionnaires had been completed and the focus group discussion with six undergraduate students had been conducted, the study concluded that social media provide the opportunity to multitask for the students and that they are the perfect tools from their perspective in that they are a good fit with their social and academic life. This research focused on the undergraduate student group without any additional specification of the sample.

\subsection{The Benefits and Drawbacks of Social Media}

In order to reveal the benefits and drawbacks of the use of social media by students, this section reviews some studies that have addressed issues regarding social media and tried to categorize them in terms of educational and social benefits or drawbacks. Regarding the educational considerations, it is common in classrooms for social media to be used. In fact, $40 \%$ of college professors encourage their students to interact with them and other students outside the classroom and inside it as part of the classroom activities (Lofgren, Shultz \& Porr, 2015).

Lin, Peng, Kim, Kim, and Larose (2011) examined the relationship between Facebook and social capital, which refers to the potential cumulated resources and benefits gained by an individual in her or his relationships with other people. Lin et al. (2011) contends that Facebook usage positively influenced international students' social capital and adjustments in the USA. For example, they found that international students had better social adjustment in their relationships with their American peers when they interacted with them using Facebook. Many studies have supported Lin et al.'s (2011) study by reaching similar results. Pollara and Zhu (2011) conducted a study to determine if social network applications would strengthen the relationships between the mentors and mentees and if these platforms increased the students' participation in dialogue outside the class. The authors used Facebook as a model to 
examine the relationships and the participations, and they found that the pairs of mentor and mentee who participated more in the created Facebook group page had a stronger relationship both online and offline than others. Also, they found that although the students believed Facebook to be an effective tool for educational purposes, they would have been less interested if the mentors had been inactive. Obviously, students appreciate Facebook, yet they will not benefit from it as much unless there are active facilitators. However, the situation is changed when the purpose of using social media is for socializing, entertainment, or professional use.

Lofgren et al. (2015) investigated the impact of LinkedIn as a supplemental teaching tool in the higher education curriculum in the Houston School of Agriculture. The study found that social media allow students to be exposed to more of the class materials; moreover, those who achieved higher grades had higher participation in LinkedIn, and that was persuasive evidence that social media have an impact on the absorption and comprehension of class materials. Moreover, Lamb and Johnson (2007) conducted a study that addressed the information skills that presented wikis as an example for it. The study emphasized the importance of wikis in the learning process for all grade levels and listed the advantages of using them in class, including providing of an environment in which groups can share their knowledge and come to consensus.

On the other hand, many in academia believe that social media have a negative impact on the educational level. Most of the fears concentrate on the distraction and on inappropriate posting content. Connolly (2011) stated that some researchers have shown a correlation between heavy Internet use and greater impassivity, less tenacity, and weaker critical thinking skills, while Lederer (2012) mentioned that distraction is the most prominent drawback of the use of social media in the classroom because it diverts students' attention away during the class. Also, social media detract from human interaction, and the student will miss the opportunity to develop face-to-face interaction skills. Another serious negative effect of social media is cyber-bulling. The high prevalence rates of cyber-bullying among students create interest among researchers working hard to highlight the subject and discuss the reasons and solutions. Whittaker and Kowalski (2015) conducted a study that addressed cyber-bullying among college students. Forty-eight percent of the participants had been victimized at least once in the last year; Twitter was the site of a high proportion of cyber-bullying with $45.5 \%$, while chat rooms had the lowest proportion at $2.3 \%$.

Far from the educational domain, the personal relationships that emerged on social media sites did not develop greatly because the privacy on these sites is weak and not highly trusted (Pardue, 2012). Also, the time that individuals spend on social media reduces their interaction with people offline.

\section{Methodology}

\subsection{Research Method}

An explanatory sequential mixed method design was used in order to provide more evidence 
about the research problem as opposed to the use of one method, which would have yielded fewer results. The population of the study consisted of the international students located in the University of North Texas, United State of America. The purposive sampling was used to select the participants. The international students' participant chosen for the research was specifically from Saudi Arabia. The total number of the participant were 91. According to Krathwohl (2009) purposive sampling is most often used. The author stated that the purposive sampling strengthened the logic of the method and if done right, it will be a good way to test the findings. The purposive sampling gives the researcher the freedom to choose the individuals.

Two instruments were used: an online structured questionnaire (quantitative) and a semi-structured interview (qualitative). In the survey, a questionnaire was adopted as a tool for collecting data from the targeted participants. The purpose for using the survey was to generalize from a sample to a population, for the purpose of making inferences about some variables. In addition, the survey design has advantages such as being an economical design and identifying attributes of the small group that can be generalized to the study population. The questionnaire was adopted from Fewkes and McCabe (2012) and modified by the authors to serve the purpose of the study. Before sending the surveys the researchers got the Institutional Review Board (IRB) Approval to use the developed survey and interview questions. The survey was sent through an instant-messaging program (WhatsApp) and accessed via Qualtrics. The questionnaire consists of 19 questions divided into three sections: first, demographic information; second, the use of social media; and third, the purpose of use. After the collection and analysis of the survey outcomes, semi-structured interviews were conducted with only four volunteering participants. The reason for using this type of instrument is to gain a deeper understanding of responses, especially if the responses are very personal to the participants. Additionally, this type of setting can make the participant more comfortable and sociable (Creswell \& Clark, 2011).

\subsection{Analysis}

The mixed method consists of both quantitative and qualitative methods. For quantitative analysis, the authors used SPSS predictive analytics software for testing frequency distributions involving simple percentages, as well as for getting Pearson's product moment correlations to examine a variety of variables in order to decide which participants to follow up with and what results needed to be explained. For the qualitative data, the researchers used research questions in order to provide a convenient and efficient way to outline the main themes and sub-themes. By means of color coding the transcripts of interviewees' responses for each section of the themes and subthemes, the researchers studied the data to extract quotations that best illustrated both themes and subthemes. To insure the qualitative reliability of the study, the researchers carried out the coding with the participation of multiple coders to reach agreement on codes. The qualitative validity of the study was insured by two type of approaches. First, the member-checking approach was used by taking the main themes and sub-themes to the interviewees to make sure that they were an accurate reflection of their experience. Second, the triangulation was applied by building evidence to verify that the themes were from several sources as well as to verify findings from both quantitative and 
qualitative surveys (Creswell \& Clark, 2011).

\section{Results}

Before starting the survey, the participants were asked if they were willing to participate; a total of 87 (95.6\%) agreed to participate, while four (4.4\%) did not agree. Moreover, owing to the purpose of the study, the participants were asked if they used social media in class; from the total 87 participants, 56 (64.4\%) said yes, while 31 (35.6\%) said no. Following the guideline by DeVellis (1991), Cronbach's alpha scores were taken to indicate high internal consistency reliability for the measurement index. The Cronbach's alpha of 27 items was 0.77 , exceeding the common threshold value of 0.70 .

\subsection{Demographic Information}

This section covers questions three to ten listed on the questionnaire. A total of 56 (64.4\%) participants completed the questionnaire, which resulted in nine invalid questionnaires, which was eliminated, leaving a total number of respondents 47 (54\%).

Table 1 shows all the demographic information of the participants. The majority of the participants were male with 34 (72.3\%) and 13 females (27.7\%). The ages of the participants were between (20 - 45); 15 participants were between 20-25 years (31.9\%), 14 participants were between 26-30 years (29.8\%), 13 participants were between 31-35 years (27.7\%), and five participants were between $36-45$ years $(10.6 \%)$. The majority of the participants, 31 (66\%) were married, while 16 participants were single (34\%). The participants were asked about their fluency in the English language; 31 (66\%) chose good, 13 (27.7\%) chose fair, and three $(6.4 \%)$ chose poor. The participants were asked about their current level of education; 30 participants (63.8\%) were at a graduate level, and only 17 (36.2\%) were at an undergraduate level. An independent-sample t-test was conducted to compare the two sub-samples. The result shows that males and females were not significantly different in terms level of satisfaction with their use of social media. 


\section{Macrothink}

Table 1. Demographic Information

\begin{tabular}{|c|c|c|}
\hline Characteristics & Respondents & $\%$ \\
\hline \multicolumn{3}{|l|}{ Gender } \\
\hline Male & 34 & 72.3 \\
\hline Female & 13 & 27.7 \\
\hline \multicolumn{3}{|l|}{ Age } \\
\hline $20-25$ & 15 & 31.9 \\
\hline $26-30$ & 14 & 29.8 \\
\hline 31-35 & 13 & 27.7 \\
\hline $36-45$ & 5 & 10.6 \\
\hline \multicolumn{3}{|l|}{ Marital Status } \\
\hline Single & 16 & 34.0 \\
\hline Married & 31 & 66.0 \\
\hline \multicolumn{3}{|l|}{ Fluency in English language } \\
\hline Poor & 3 & 6.4 \\
\hline Fair & 13 & 27.7 \\
\hline Good & 31 & 66.0 \\
\hline \multicolumn{3}{|l|}{ Level of Education } \\
\hline Undergraduate & 17 & 36.2 \\
\hline Graduate & 30 & 63.8 \\
\hline \multicolumn{3}{|l|}{ Current Year of Study } \\
\hline One-year & 12 & 25.5 \\
\hline Two-years & 11 & 23.4 \\
\hline Three-years & 12 & 25.5 \\
\hline Four-years & 12 & 25.5 \\
\hline \multicolumn{3}{|l|}{ Discipline } \\
\hline Social Sciences & 19 & 40.4 \\
\hline Physical Sciences & 4 & 8.5 \\
\hline Humanities Sciences & 5 & 10.6 \\
\hline Applied Sciences & 13 & 27.7 \\
\hline Other & 6 & 12.8 \\
\hline
\end{tabular}

\subsection{Use of Social Media}

This section covers questions 11 to 20 listed on the questionnaire. These data are summarized in Tables 2, 3, and 4.

The main question for this research was the following: What is the experience of the international students who use social media in the classroom? Regarding this research question, the participants were asked how many hours they spent on social media per day. The largest group, 16 (34\%) chose between 5-6 hours, 12 (25.5\%) used social media between 3-4 hours, nine (19.1\%) chose 6-7 hours, six (12.8\%) chose 8+ hours, and only four used 
social media between 1-2 hours per day. Moreover, in question 12, the participants were asked how many minutes they spent on social media in class. The largest group of the participants, 27 (57.4\%), used social media between 1-10 minutes, 13 (27.7\%) used them between 11-30 minutes, five (10.6\%) used them between 31-60 minutes, and only two (4.3\%) used social media between 61-120 minutes. Additionally, the survey showed that the largest group of participants that consist of 40\%, had 50-100 social media (followers, subscribers, and users) followed by $31.9 \%$ of participants, who had 101-500 social media (followers, subscribers, and users).

In the interviews, all interviewees reported not using social media in class when they had in Saudi Arabia because there were some restrictions from professors or there was insufficient social media access. In addition, the teaching style did not give them time to access their social media. However, the interviewees explained that they used social media during their classes in the US because they wanted to be more connected and to be informed about family and country news. Two of the interviewees explained that the reason they used the social media during the class was that they were driven by curiosity about family and country news.

The first sub-question for this research was the following: What social media do international students use the most in the classroom? Regarding this research question, the participants were asked, "How frequently do you use the following social media in class?" Table 2 displays nine types of social media tools. By reviewing the information in the table, the authors found that the top social media tools were WhatsApp, with $42.6 \%$, followed by Twitter with $21.3 \%$, then YouTube with $14.9 \%$, followed by Instagram with $12.8 \%$, then Wikipedia with $8.5 \%$ and finally Facebook with $4.3 \%$. It was somewhat surprising that YouTube was in the top three since that platform requires audio for the user to have a full experience.

Table 2. Use of Social Media Tools in Class

\begin{tabular}{ccccccc}
\hline \multirow{2}{*}{ Rank } & Social Media Tools & $\mathbf{N}$ & $\mathbf{R}$ & $\mathbf{S}$ & $\mathbf{F}$ & $\mathbf{V F}$ \\
& & $\mathbf{( \% )}$ & $\mathbf{( \% )}$ & $\mathbf{( \% )}$ & $\mathbf{( \% )}$ & $\mathbf{( \% )}$ \\
\hline 1 & WhatsApp & 8.5 & 14.9 & 17 & 17 & 42.6 \\
2 & Twitter & 29.8 & 10.6 & 25.5 & 12.8 & 21.3 \\
3 & YouTube & 46.8 & 17 & 8.5 & 12.8 & 14.9 \\
4 & Instagram & 34 & 21.3 & 19.1 & 12.8 & 12.8 \\
5 & Wikipedia & 48.9 & 17.0 & 12.8 & 12.8 & 8.5 \\
6 & Facebook & 31.9 & 29.8 & 25.5 & 8.5 & 4.3 \\
7 & Snapchat & 51.1 & 17 & 21.3 & 8.5 & 2.1 \\
8 & LinkedIn & 72.3 & 4.3 & 17 & 6.4 & - \\
9 & Pinterest & 85.1 & 8.5 & 4.3 & 2.1 & - \\
10 & Other & 59.6 & 19.1 & 14.9 & 6.4 & - \\
\hline
\end{tabular}

The previous categories were assigned to different items: $\mathrm{N}=$ (Never), $\mathrm{R}=$ (Rarely), $\mathrm{S}=$ (Sometime), $\mathrm{F}=$ (Frequently), and VF= (Very Frequently). 
All of the interviewees agreed that WhatsApp, Twitter, and Instagram were the most used social media tools in class. One interviewee stated, "WhatsApp is so fast, so easy to use and I really prefer to use it more than other tools." Moreover, another interviewee mentioned that he depended on Twitter to be kept up to date with the latest news and events in his country.

The second sub-question for this research was the following: Why do international students use social media? In regard to this research question, Table 3 outlines the reasons behind the use of social media in class by the international students. It shows that, while in class, international students use social media most often for communication purposes, at $38.3 \%$. Twenty percent of the participants reported they used it for entertainment. Finally, only nine percent said that they used it for education.

Table 3. Use Statements of Social Media in Class

\begin{tabular}{|c|c|c|c|c|c|}
\hline Statement & $\begin{array}{c}\text { SD } \\
(\%)\end{array}$ & $\begin{array}{c}D \\
(\%)\end{array}$ & $\begin{array}{l}\text { ND } \\
(\%)\end{array}$ & $\begin{array}{c}A \\
(\%)\end{array}$ & $\begin{array}{c}\text { SA } \\
(\%)\end{array}$ \\
\hline Using social media & 6.4 & 23.4 & 3.09 & 29.8 & 9 \\
\hline Using social media for communication & 2.1 & 6.4 & 8.5 & 44.7 & 38.3 \\
\hline Using social media for entertainment & 4.3 & 6.4 & 17 & 53.2 & 20 \\
\hline
\end{tabular}

The previous categories were assigned to different items: $\mathrm{SD}=$ (Strongly Disagree), $\mathrm{D}=($ Disagree), $\mathrm{ND}=$ (Neither Agree nor Disagree), $\mathrm{A}=$ (Agree), and SA= (Strongly Agree)

Table 4 outlines the reasons behind the use of social media outside of the class by the international students participating in the study. It shows that, while out of the class, the participants used social media most often for communication purposes at $38.3 \%$, which is exactly the same as the percentage for the use of social media in class. Thirty-four percent of the participants reported they used social media for entertainment. Finally, 28\% used them for educational purposes.

Table 4. Use Statements of Social Media Outside of the Class

\begin{tabular}{lccccc}
\hline \multicolumn{1}{c}{ Statement } & SD & D & ND & A & SA \\
& $(\mathbf{\% )}$ & $\mathbf{( \% )}$ & $\begin{array}{c}\mathbf{( \% )} \\
\mathbf{( \% )}\end{array}$ & $\begin{array}{c}(\%) \\
\mathbf{( \% )}\end{array}$ \\
\hline Using social media for education & 6.4 & 23.4 & 3.09 & 29.8 & 9 \\
Using social media for communication & 2.1 & 6.4 & 8.5 & 44.7 & 38.3 \\
Using social media for entertainment & 4.3 & 6.4 & 17 & 53.2 & 20 \\
\hline
\end{tabular}

When asked whether international students felt connected with their family or friends or felt well-informed, as a result of using social media in class, the majority of participants stated they felt connected with their family when using social media in class. This was followed by 23.4\% who stated that they felt connected with their friends. Finally, at the same age of $23.4 \%$, the participants felt that they were informed by using social media in class.

Pearson's product moment correlations were conducted to examine the relationship between social media use satisfaction and age. The results revealed a significant medium positive 
correlation between social media use satisfaction and age, $r=0.487(\mathrm{p}<.001)$, suggesting that when the age increased, the level of satisfaction social media use increasedl.

Interviewees indicated they used social media in class for many reasons. One interviewee said, "When I get bored! While I'm in class and your professor is telling about something is not related to the class or talks about something you don't have an interest in." Another interviewee said, "Sometimes it is hard to be focused in class, so it helps to run away from the stress you have." An important result was that all interviewees said that they used social media in class because they did not want to be disconnected from their family and friends or their social media world.

The third sub-question for this research was the following: What benefits and drawbacks do international students see in their use of social media? Regarding this research question, as discussed in connection to the previous results, the majority of participants used social media in class, and most of the participant did not use social media for an educational purpose. Therefore, Figure 1 indicates that the majority of participants agreed that social media was a distraction in class, which presents an interesting contrast in light of the high use of social media in class by the same participants. Although social media can be a distraction tool in class, one interesting finding from the interview is that social media can be useful in class for some international students in certain departments (e.g., art education). For example, when one interviewee was asked about the advantages, she said, "Get some helpful/new information and improve my skills," and "I use it to understand the lecture or share the class something I find it interesting.”

Compared to the advantages, there were more statements relating to disadvantages. Supporting the general statement about how social media can be a cause of distraction, the interviewees revealed that getting bad news during class can affect their concentration or cause them to leave the class. For example, one of the interviewees talked about his experience of receiving bad news in the form of images of an accident his cousin had had through the Snapchat application. Another interviewee stated that by using social media he lost attention in class, which affected his performance and participation grade.

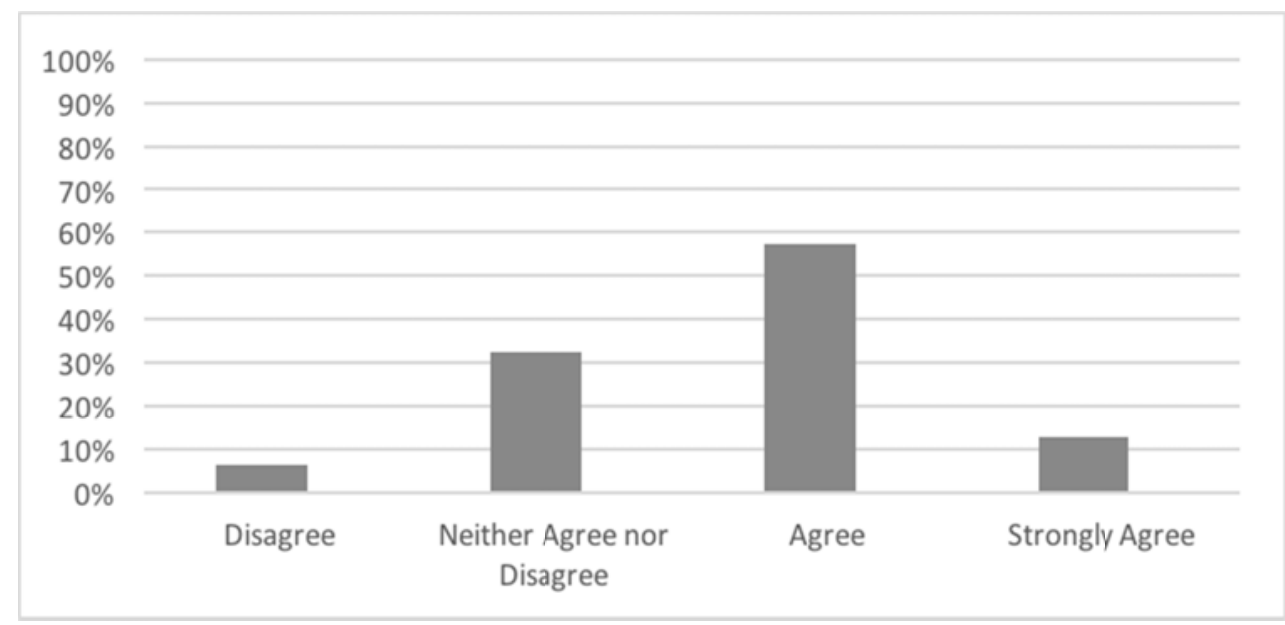

Figure 1. Social Media as a Distraction Tool Results 


\section{Discussion}

\subsection{Use of Social Media}

Social media are a group of Internet-based applications, which were built on the conceptual and technological fundamentals of Web 2.0, and which make possible the creation and exchange of users' information and content (Kaplan \& Haenlein, 2010). The worldwide usage of social media is increasing daily. Social media are the most popular online activity with high user engagement rates and expanding mobile possibilities. The evolution of handheld smart devices and mobile applications enables users to easily access all social media services.

This study shows that the use of social media by the international students increased when they began to study in the United States, particularly the use of social media during class time. Lefdahl-Davis and Perrone-Mcgovern (2015) indicated a reason for this by saying that international students have higher expectations about freedom in the education environment in United States. International students indicate that they feel lonely and geographically isolated and that they miss their families and friends. Robertson, Line, Jones, and Thomas (2000) stated that international students feel culturally isolated from the place in which they study. In addition, the consequences of being isolated may contribute to their being in a "small-world" based on their virtual environment (Sin \& Kim, 2013, p. 2). In order to bridge this gap, international students use social media even at times when they should not, such as during the class. According to Ye (2006), international students use social networks because of their immediate need for social support after they have moved far away from their traditional social net, their families and relatives.

When international students were asked what type of social media they used the most, the largest group of participants used WhatsApp with 42.6\%, compared with eight other social media tools such as Facebook, Twitter, Instagram, and Snapchat. WhatsApp is a cross-platform instant messaging service for smartphones. The application provides the users with a simple interface that allows them to interact with each other free of charge through audio/video files, text messaging, and images. According to Statista (2016b), WhatsApp is an alternative to carrier-billed text messaging, especially for international or group messaging. The article indicated that currently WhatsApp has 700 million users, and it is in the third place after Facebook, with 1.4 billion users. The article also shows that Saudi Arabia is one of the top countries in the use of WhatsApp, which accounts for $56 \%$ of total social media use in that country. This supports the finding of this study that the majority of international student use WhatsApp to connect with their family and friends.

\subsection{Purpose of Social Media Use}

Social media can be used for a variety of reasons. They can be used to get latest news and trends from around the world as well as to connect and share information with family and friends. As Fewkes and McCabe (2012) and Lenhart, Purcell, Smith, and Zickuhr (2010) have pointed out, the majority of users are undeniably using social media for a range of uses. Moreover, when the participants were asked why they used social media, the majority indicated that they used social media to communicate with their family and friends. In relation to this fact, Sin and Kim (2013) indicated that social media use with family and 
friends has positively given support and aid in adjustment to international students.

When the participants were asked what the purposes of using social media were in class or out of the class, $9 \%$ of the participants indicated that they used social media for educational purposes in class, while $28 \%$ of participants indicated that they used social media for educational purposes out of the class. Perhaps, what is missing from the educational environment for international students is families and friends, and their virtual presence is a must. Thus, use of social media in class should be integrated with the learning environment, especially in relation to the motivation of use, which can potentially provide success in overcoming most reason for having a small-world context. That would be consistent with Lofgren's et al. (2015) finding that using social media in an education setting has a positive impact on students' absorption and comprehension of class material.

\section{Conclusion}

This study is an attempt to understand the phenomenon of social media use and the advantages and disadvantages of using social media during class. The study showed that the majority of international students used social media in the class for variety of reasons. The reasons were varied among educational, communicative, and entertainment purposes, yet there was near agreement that WhatsApp and Twitter were the most popular social media tools for international students.

However, many international students see that using social media during the class is a distraction factor for their concentration. Based on the results of this study, the researchers believe that social media could be a very helpful tool if they were integrated with the learning environment because social media are now becoming the most used platforms among students in general and international students in specific. A rising power, social media are a double-edged sword because students can use them in a positive or negative way; therefore, the academic community should strive to benefit from them and reduce their negative effects by conducting studies and making recommendations regarding this issue.

\section{Acknowledgement}

The research was developed with the help and supervision of Dr. Lin Lin, Department of Learning Technologies, College of Information, University of North Texas.

\section{References}

Baggett, S., \& Williams, M. (2012). Students behaviors and opinions regarding the use of social media, mobile technologies, and library research. Digital Library and Archives, 58(1). Retrieved from http://scholar.lib.vt.edu/ejournals/VALib/v58_n1/baggett.html

Boyd, D. M., \& Ellison, N. B. (2007). Social network sites: Definition, history, and scholarship. Journal of Computer-Mediated Communication, 13(1), 210-230. 
http://dx.doi.org/10.1109/EMR.2010.5559139

Connolly, M. (2011, October) Benefits and drawbacks of social media in education. Retrieved from Wisconsin Center for Education Research: http://www.wcer.wisc.edu/news/coverstories/2011/benefits_and_drawbacks.php

Creswell, J. W., \& Clark, V. L. P. (2012). Designing and conducting mixed methods research (2nd ed.). Thousand Oaks, Calif: Sage Publications.

DeVellis, R. F. (1991). Scale development. Newbury Park, NJ: Sage Publications.

Fewkes, A. M., \& McCabe, M. (2012). Facebook: learning tool or distraction? Journal of Digital Learning in Teacher Education, 28(3), 92-98.

Kaplan, A. M., \& Haenlein, M. (2010). Users of the world, unite! The challenges and opportunities of social media. Business horizons, 53(1), 59-68. http://dx.doi.org/10.1016/j.bushor.2009.09.003

Krathwohl, D. R. (2009). Methods of educational and social science research: The logic of methods (3rd ed.). Long Grove, IL: Waveland Press.

Lamb, A., \& Johnson, L. (2007). An information skills workout: Wikis and collaborative writing. Teacher Librarian, 34(5), 57-59.

Lefdahl-Davis, E. M., \& Perrone-McGovern, K. M. (2015). The cultural adjustment of Saudi women international students: A qualitative examination. Journal of Cross-Cultural Psychology, 46(3) 1-29. http://dx.doi.org/10.1177/0022022114566680

Lenhart, A., Purcell, K., Smith, A., \& Zickuhr, K. (2010). Social media and young adults. Washington, DC: Pew Internet \& American Life Project.

Lin, J., Peng, W., Kim, M., Kim, S. Y., \& LaRose, R. (2011). Social networking and adjustments among international students. New Media \& Society, 14(3), 421-440. http://dx.doi.org/10.1177/1461444811418627

Lofgren, E. A., Shultz, A. M., \& Porr, C. S. (2015). Social media and equine science: The effect of LinkedIn on in-class engagement of equine higher education students 1 . NACTA Journal, 59(3), 208-212.

Pardue, M. S. (2012). The one another project: A quantitative study of north American Christian college and seminary students' perception of social media's effect on their biblical interpersonal relationships. (Doctoral dissertation). Retrieved from ProQuest Dissertations \& Theses Database.

Pollara, P., \& Zhu, J. (2011). Social Networking and Education: Using Facebook as an Edusocial Space. In Proceedings of Society for Information Technology \& Teacher Education International Conference 2011 (pp. 3330-3338). Chesapeake, VA: AACE.

Robertson, M., Line, M., Jones, S., \& Thomas, S. (2000). International students, learning environments and perceptions: A case study using the Delphi technique. Higher 
education research and development, 19(1), 89-102. http://dx.doi.org/10.1080/07294360050020499

Sandhu, D. S., \& Asrabadi, B. R. (1994). Development of an acculturative stress scale for international students: Preliminary findings. Psychological reports, 75(1), 435-448. http://dx.doi.org/10.2466/pr0.1994.75.1.435

Sin, S. j., \& Kim, K. (2013). International students' everyday life information seeking: the informational value of social networking sites. Library \& Information Science Research, 35(2), 107-116. http://dx.doi.org/10.1016/j.lisr.2012.11.006

Statista (2016a). Leading social networks worldwide as of January 2016, ranked by number of active users. Retrieved from http://www.statista.com/statistics/272014/global-socialnetworks-ranked-by-number-of-users/

Statista (2016b). Share of mobile internet users in selected countries who are active WhatsApp users as of 4th quarter 2014. Retrieved from http://www.statista.com/ statistics/291540/mobile-internet-user-whatsapp/

Walaski, P. (2013). Social media: Powerful tools for SH\&E professionals. Professional Safety, 58(4), 40-49. Retrieved from: https://www.asse.org/professionalsafety/pastissues/058/04/ F1 Wala_0413.pdf

Whittaker, E., \& Kowalski, R. (2015). Cyberbullying via Social media. Journal of School Violence, 14(1), 11-29. http://dx.doi.org/10.1080/15388220.2014.949377

Ye, J. (2006). An examination of acculturative stress, interpersonal social support, and use of online ethnic social groups among Chinese international students. Howard Journal of Communications, 17(1), 1-20. http://dx.doi.org/10.1080/10646170500487764

\section{Appendix}

Appendix 1. Survey Question for International Student Using Social Media During Classes

Appendix 2. Follow-up Interview Questions

Appendix 3. University of North Texas Institutional Review Board Instruments Approval

\section{Copyright Disclaimer}

Copyright for this article is retained by the author(s), with first publication rights granted to the journal.

This is an open-access article distributed under the terms and conditions of the Creative Commons Attribution license (http://creativecommons.org/licenses/by/3.0/). 